Pacific Journal of Mathematics

Ortiz how 


\title{
ON DOUBLY HOMOGENEOUS ALGEBRAS
}

\author{
LOWELL SWEET
}

The algebras to be discussed are assumed to be finite dimensional and not necessarily associative. If $A$ is an algebra over a field $K$ let $\operatorname{Aut}(A)$ denote the group of algebra automorphisms of $A$. We define $A$ to be doubly homogeneous if Aut $(A)$ is doubly transitive on the one-dimensional subspaces of $A$. Also a doubly homogeneous algebra $A$ is said to be nontrivial if $A^{2} \neq 0$ and dimension $A>1$. It is shown that the only nontrivial doubly homogeneous algebra is unique up to isomorphism.

An algebra $A$ is said to be homogeneous if Aut $(A)$ acts transitively on the one-dimensional subspaces of $A$. The reader is referred to the author's previous paper [1] for a discussion of homogeneous algebras and a bibliography of the related literature.

An arbitrary algebra $A$ is said to be nonzero if $A^{2} \neq 0$. If the nonzero elements of $A$ form a quasi-group under multiplication then we say that $A$ is a quasi-division algebra.

Lemma. If $A$ is a nonzero doubly homogeneous algebra over a field $K$ then $A$ is a quasi-division algebra.

Proof. Let $\operatorname{dim} A=n$. If $n=1$ then $A$ is isomorphic to $K$ and the result is obvious and so we assume that $n>1$. Let $a$ be any element of $A$. We claim that if $b \notin K a$ then $a b \neq 0$. For if $a b=0$ the doubly homogeneity condition implies that $a c=0$ for all $c$ such that $c \notin K a$. But then in particular $b+a \notin K a$ and so $a(b+a)=0$ which implies that $a^{2}=0$ and thus $a A=0$. In this case the homogeneity condition implies that $A^{2}=0$ which is a contradiction and the claim is verified.

Now suppose that $a^{2}=0$. Then the homogeneity condition implies that $x^{2}=0$ for all $x \in A$. Suppose there exists $b \notin K a$ such that

$$
a b \in K a \text {. }
$$

Then by doubly homogeneity we would also have

$$
(a+b) b \in K(a+b)
$$

and $b^{2}=0$ implies that

$$
a b \in K a \cap K(a+b)=\{0\}
$$

which is impossible. Fix some $b \notin K a$. Let $c$ be any nonzero element 
of $A$. Then there must exist $\alpha \in \operatorname{Aut}(A)$ such that

$$
\alpha(a b) \in K c
$$

and

$$
\alpha(a) \in K a
$$

This implies that $L_{a}$ (left multiplication by $a$ ) is a surjective map which is impossible and so $a^{2} \neq 0$. Hence $L_{a}$ is invertible and the homogeneity condition implies that $A$ is a quasi-division algebra.

THEOREM. If $A$ is a nonzero doubly homogeneous algebra over a field $K$ then either $A \cong K$ or $K=G F(2)$ and $A$ is isomorphic to the following algebra

\begin{tabular}{c|cc} 
& $a$ & $b$ \\
\hline$a$ & $a$ & $a+b$ \\
$b$ & $a+b$ & $b$
\end{tabular}.

Proof. If $\operatorname{dim} A=1$ then clearly $A \cong K$. If $\operatorname{dim} A=2$ then $A$ must be contained in the authors list of 2-dimensional homogeneous algebras [1] and it is easily checked that the only possibility is that $K=G F(2)$ and $A$ is isomorphic to the following algebra

\begin{tabular}{c|cc} 
& $a$ & $b$ \\
\hline$a$ & $a$ & $a+b$ \\
$b$ & $a+b$ & $b$
\end{tabular}.

Hence to prove the theorem it is sufficient to show that there exist no nonzero doubly homogeneous algebras of dimension $n>2$.

Let $A$ be a nonzero doubly homogeneous algebra of dimension $n>2$. If $a$ is any fixed nonzero element in $A$ then the lemma implies that the equation $a x=a$ must have a unique solution, say $b$ and the doubly homogeneity condition now implies that $b \in K a$. It follows that $A$ is a nonzero, power-associative, homogeneous algebra and so Theorem 7 of the author's previous paper [1] implies that $K=G F(2)$.

Now let $a$ and $b$ be any two distinct nonzero elements of $A$ and let $A_{1}=\langle a, b\rangle$ be the subalgebra of $A$ generated by $a$ and $b$. It can be shown that $A_{1}$ is also a doubly homogeneous algebra and it is generated by any two distinct nonzero elements. Hence only the identity automorphism of $A_{1}$ can fix two distinct nonzero elements of $A_{1}$ and so Aut $\left(A_{1}\right)$ is sharply doubly transitive on $A_{1} \mid\{0\}$. Hence the order of Aut $\left(A_{1}\right)$ must be even and so $\operatorname{Aut}\left(A_{1}\right)$ must contain at least one involution, say $\alpha$. This involution $\alpha$ fixes at most 1 one- 
dimension subspace of $A_{1}$. But since any involution acting on a vector space $V$ over a field of characteristic 2 fixes vectorwise a subspace of dimension $\geqq 1 / 2 \operatorname{dim} V$ this forces $\operatorname{dim} A_{1}=2$ and so we may assume that

$$
a b=a+b .
$$

But since $A$ is doubly homogeneous it follows that

$$
\begin{array}{clrl}
x^{2} & =x & & \text { for all } x \in A \\
x y & =x+y & & \text { whenever } y \notin K x .
\end{array}
$$

Now since $n>2$ we can choose three independent vectors $a, b, c \in A$. But then

$$
(a+b) c=a+b+c
$$

and

$$
a c+b c=a+c+b+c=a+b
$$

which is impossible and the proof is complete.

\section{REFERENCE}

1. L. G. Sweet, On homogeneous algebras, (the previous paper).

Received September 13, 1974 and in revised form November 21, 1974. The author would like to thank the referee for his suggestion. This work was supported in part by the NRC Grant A9119 and the Senate Research Committee of the University of Prince Edward Island.

University of Prince EdWard Island 



\title{
PACIFIC JOURNAL OF MATHEMATICS
}

\section{EDITORS}

RichaRd ARENS (Managing Editor)

University of California

Los Angeles, California 90024

\section{R. A. Beaumont}

University of Washington

Seattle, Washington 98105
J. DUGUNDJI

Department of Mathematics University of Southern California Los Angeles, California 90007

D. Gilbarg and J. Milgram

Stanford University

Stanford, California 94305

\section{ASSOCIATE EDITORS}
E. F. BECKENBACH
B. H. NeUmanN
F. WOLF
K. YoshIDA

\section{SUPPORTING INSTITUTIONS}

\author{
UNIVERSITY OF BRITISH COLUMBIA \\ CALIFORNIA INSTITUTE OF TECHNOLOGY \\ UNIVERSITY OF CALIFORNIA \\ MONTANA STATE UNIVERSITY \\ UNIVERSITY OF NEVADA \\ NEW MEXICO STATE UNIVERSITY \\ OREGON STATE UNIVERSITY \\ UNIVERSITY OF OREGON \\ OSAKA UNIVERSITY
}

\author{
UNIVERSITY OF SOUTHERN CALIFORNIA \\ STANFORD UNIVERSITY \\ UNIVERSITY OF TOKYO \\ UNIVERSITY OF UTAH \\ WASHINGTON STATE UNIVERSITY \\ UNIVERSITY OF WASHINGTON \\ AMERICAN MATHEMATICAL SOCIETY
}

The Supporting Institutions listed above contribute to the cost of publication of this Journal, but they are not owners or publishers and have no responsibility for its content or policies.

Mathematical papers intended for publication in the Pacific Journal of Mathematics should be in typed form or offset-reproduced, (not dittoed), double spaced with large margins. Underline Greek letters in red, German in green, and script in blue. The first paragraph or two must be capable of being used separately as a synopsis of the entire paper. Items of the bibliography should not be cited there unless absolutely necessary, in which case they must be identified by author and Journal, rather than by item number. Manuscripts, in triplicate, may be sent to any one of the editors. Please classify according to the scheme of Math. Reviews, Index to Vol. 39. All other communications should be addressed to the managing editor, or Elaine Barth, University of California, Los Angeles, California, 90024.

The Pacific Journal of Mathematics expects the author's institution to pay page charges, and reserves the right to delay publication for nonpayment of charges in case of financial emergency.

100 reprints are provided free for each article, only if page charges have been substantially paid. Additional copies may be obtained at cost in multiples of 50 .

The Pacific Journal of Mathematics is issued monthly as of January 1966. Regular subscription rate: $\$ 72.00$ a year (6 Vols., 12 issues). Special rate: $\$ 36.00$ a year to individual members of supporting institutions.

Subscriptions, orders for back numbers, and changes of address should be sent to Pacific Journal of Mathematics, 103 Highland Boulevard, Berkeley, California, 94708.

PUBLISHED BY PACIFIC JOURNAL OF MATHEMATICS, A NON-PROFIT CORPORATION

Printed at Kokusai Bunken Insatsusha (International Academic Printing Co., Ltd.), 8-8, 3-chome, Takadanobaba, Shinjuku-ku, Tokyo 160, Japan.

Copyright (C) 1975 by Pacific Journal of Mathematics Manufactured and first issued in Japan 


\section{Pacific Journal of Mathematics}

\section{Vol. 59, No. $2 \quad$ June, 1975}

Aharon Atzmon, A moment problem for positive measures on the unit disc ........

Peter W. Bates and Grant Bernard Gustafson, Green's function inequalities for

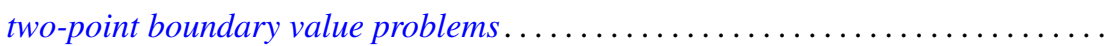

Howard Edwin Bell, Infinite subrings of infinite rings and near-rings ...........

Grahame Bennett, Victor Wayne Goodman and Charles Michael Newman, Norms of

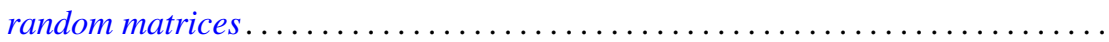

Beverly L. Brechner, Almost periodic homeomorphisms of $E^{2}$ are periodic.........

Beverly L. Brechner and R. Daniel Mauldin, Homeomorphisms of the plane ........

Jia-Arng Chao, Lusin area functions on local fields ......................

Frank Rimi DeMeyer, The Brauer group of polynomial rings ...............

M. V. Deshpande, Collectively compact sets and the ergodic theory of

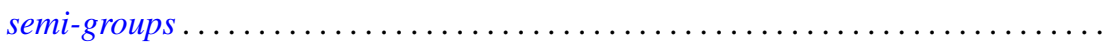

Raymond Frank Dickman and Jack Ray Porter, $\theta$-closed subsets of Hausdorff

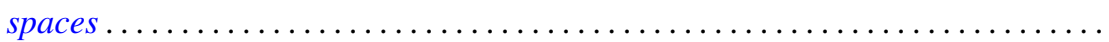

Charles P. Downey, Classification of singular integrals over a local field .......... 407

Daniel Reuven Farkas, Miscellany on Bieberbach group algebras . . . . . . . . . . . .

Peter A. Fowler, Infimum and domination principles in vector lattices . . . . . . . . . .

Barry J. Gardner, Some aspects of T-nilpotence. II: Lifting properties over

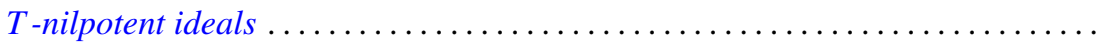

Gary Fred Gruenhage and Phillip Lee Zenor, Metrization of spaces with countable

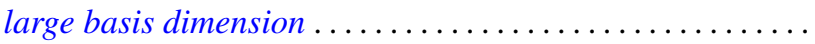

J. L. Hickman, Reducing series of ordinals...

Hugh M. Hilden, Generators for two groups related to the braid group ...

Tom (Roy Thomas Jr.) Jacob, Some matrix transformations on analytic sequence

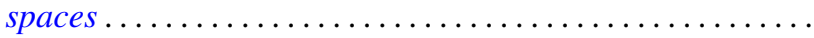

Elyahu Katz, Free products in the category of $k_{w}$-groups . .....

Tsang Hai Kuo, On conjugate Banach spaces with the Radon-Nikodým property...

Norman Eugene Liden, $K$-spaces, their antispaces and related mappings ...

Clinton M. Petty, Radon partitions in real linear spaces ........

Alan Saleski, A conditional entropy for the space of pseudo-Menger maps ....

Michael Singer, Elementary solutions of differential equations .

Eugene Spiegel and Allan Trojan, On semi-simple group algebras. I. . .

Charles Madison Stanton, Bounded analytic functions on a class of open Riemann

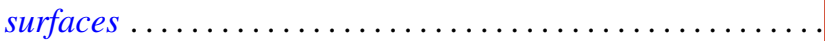

Sherman K. Stein, Transversals of Latin squares and their generalizations ....

Ivan Ernest Stux, Distribution of squarefree integers in non-linear sequences . . .

Lowell G. Sweet, On homogeneous algebras ................

Lowell G. Sweet, On doubly homogeneous algebras .......... .

Florian Vasilescu, The closed range modulus of operators ......

Arthur Anthony Yanushka, A characterization of the symplectic groups $\operatorname{PSp}(2 m, q)$

as rank 3 permutation groups... 